\title{
Enfermedad de von Economo. Caso clínico
}

\author{
SABRINA F. VADALÁ ${ }^{1}$, DÉBORA PELLEGRINI ${ }^{1}$, \\ EMANUEL D. SILVA ${ }^{2}$, DIEGO MIÑARRO ${ }^{2}$, BÁRBARA C. FINN ${ }^{1}$, \\ JULIO E. BRUETMAN ${ }^{1}$, GABRIEL NÁPOLI ${ }^{2}$, PABLO YOUNG ${ }^{1}$
}

\section{Lethargic encephalitis. Report of one case}

Lethargic encephalitis (LE) is a Central Nervous System disorder following an upper respiratory tract infection, characterized by sleep disturbances, clinical symptoms corresponding to basal ganglia involvement and in some cases, neuropsychiatric sequelae. We report a 18-year-old male with a history of sinusitis treated with azithromycin, two weeks before, presenting with fever, headache, confusion and myoclonus. Urine analysis was positive for cannabis. Cerebrospinal fluid analysis showed mononuclear pleiocytosis $\left(109 \times \mathrm{mm}^{3}\right)$ and an increase in protein concentration of 1.6 $\mathrm{g} / \mathrm{dl}$. Forty eight hours after admission, the patient required mechanical ventilation and subsequently a status epilepticus appeared. Ten days later, fever, rigidity and resting tremor appeared. A magnetic resonance imaging showed hyperintensities in FLAIR sequence in the right insular cortex. The patient continued with extreme rigidity, catatonia and mutism. Considering the possibility of a LE, methylprednisolone $1 \mathrm{~g} /$ day was administered for five consecutive days followed by prednisone $40 \mathrm{mg} /$ day, observing a dramatic improvement of rigidity and tremors.

(Rev Med Chile 2013; 141: 531-534).

Key words: Encephalitis; Encephalitis lethargica type Parkinsonism; Status epilepticus.

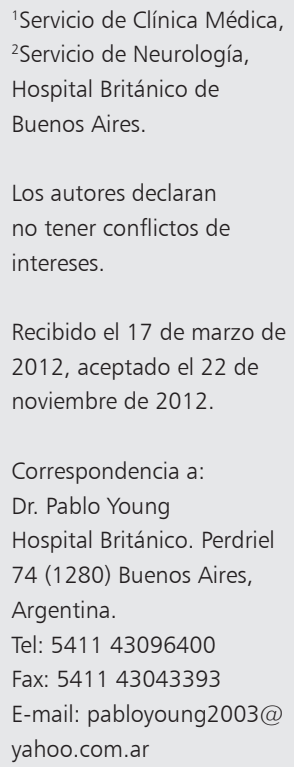

E n 1917, Constantin von Economo (18761931) describió la encefalitis letárgica (EL) como un trastorno del sistema nervioso central que sigue a un cuadro de vías aéreas superiores y se manifiesta por desórdenes del sueño, signos clínicos correspondientes a compromiso de los ganglios basales y en algunos casos secuelas neuropsiquiátricas ${ }^{1,2}$. Presentamos un caso internado en el Hospital Británico, y una revisión de la literatura.

\section{Caso clínico}

Paciente de sexo masculino de 18 años de edad con antecedente de un viaje a la ciudad de Bariloche dos semanas previas a la internación, posterior a la cual presentó cuadro de rinosinusitis. Recibió azitromicina $500 \mathrm{mg} /$ día por cinco días con resolución completa de los síntomas. Posteriormente, desarrolló fiebre, cefalea, síndrome confusional y mioclonías. Se realizó una tomografía de cerebro (TC), y una analítica de laboratorio (hemograma, ionograma, pruebas hepáticas, glicemia, urea, creatinina, magnesio, calcio, fósforo, creatinkinasa, velocidad de sedimentación globular, función tiroidea, gases arteriales y sedimento urinario) todos resultaron normales. El toxicológico en orina fue positivo para cannabis en dos oportunidades. Se efectuó una punción lumbar (PL) que evidenció líquido cefalorraquídeo (LCR) cristal de roca con pleocitosis mononuclear $\left(109 \mathrm{~mm}^{3}\right)$; e hiperproteinorraquia $(1,6 \mathrm{~g} / \mathrm{dl})$. Las determinaciones en LCR en búsqueda de leptospira, enterovirus, virus Herpes simplex, Herpes 6 y 7, varicela zoster, encefalitis de St Louis, mycoplasma, sífilis y tuberculosis arrojaron resultados negativos. Asimismo fueron negativos hemocultivos, urocultivos, serologías de hepatitis, de virus de inmunodeficiencia humana, de virus de Epstein Barr, de citomegalovirus, y parvovirus B 19. El hisopado nasofaríngeo fue negativo para virus respiratorios. Se determinaron factor anti-nuclear, complemento, anticuerpos anti-cardiolipinas, látex con resultados normales. 
La estreptolisina O (ASTO) fue $<1: 170$.

Se inició tratamiento con ceftriaxona, vancomicina y aciclovir.

A las 48 h de internación, evolucionó con deterioro del sensorio y postura de descerebración con requerimiento de asistencia respiratoria mecánica. El electroencefalograma (EEG) mostró lentificación difusa del ritmo de base y posteriormente evolucionó con actividad epileptiforme bilateral compatible con status epiléptico no convulsivo por lo que se inició ácido valproico a razón de 30 $\mathrm{mg} / \mathrm{Kg}$ como dosis de carga y $1.500 \mathrm{mg} /$ día como mantenimiento; ante la persistencia de actividad epileptiforme se adicionó levetiracetam que se usó a dosis de $2.000 \mathrm{mg} /$ día dividido en dos tomas. Se extubó a los cinco días con buena tolerancia.

Presentó fiebre en contexto de derrame pleural (exudado no complicado con cultivo negativo).

Al décimo día evolucionó con rigidez y bradicinesia progresivas, agregando temblor de reposo a $6 \mathrm{~Hz}$. Se repitió $\mathrm{TC}$ de cerebro que no evidenció cambios con respecto a estudio previo. La resonancia magnética nuclear (RM) de cerebro mostró imágenes hiperintensas en secuencia FLAIR (Fluid attenuated inversion recovery) y T2 en ambas cortezas insulares a predominio derecho (Figura 1) sin realce luego de la administración de gadolinio. Se interpretó el cuadro como parkinsonismo postencefalítico y se inició L-dopa. Persistió con fiebre, temblores generalizados y rigidez, con mínima respuesta a L-dopa/carvidopa que se usó a razón de 4 comprimidos diurnos de 100/25 mg administrados cada $3 \mathrm{~h}$. Se realizó una prueba de apomorfina con respuesta negativa. Se aumentó dosis de L-dopa hasta $1.000 \mathrm{mg} /$ día en 4 tomas de 250/25 mg separadas por $3 \mathrm{~h}$. Se repitieron punción lumbar, urocultivo, hemocultivos, radiografía de tórax y toxina para Clostridium difficile en materia fecal, todos con resultados normales.

Continuó con rigidez extrema, catatonía, flexibilidad cérea y mutismo. Días más tarde presentó cinesia paradojal, por la cual el paciente daba muestras de comprender órdenes pero no poder realizar actos motores; al arrojarle un globo sobre la cara, sin embargo, era capaz de tomarlo con ambas manos. Se colocó sonda nasoenteral para alimentación ya que había bajado $15 \mathrm{~kg}$ durante la internación. Ante la posibilidad de EL se administraron pulsos de metilprednisolona a dosis de $1 \mathrm{~g}$ por día por 5 días consecutivos, continuando posteriormente con meprednisona $40 \mathrm{mg}$ con

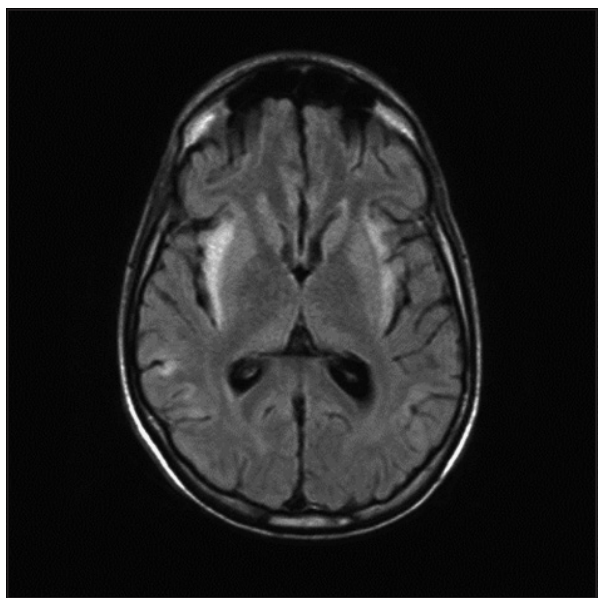

Figura 1. La RM muestra imágenes hiperintensas en secuencia FLAIR en ambas cortezas insulares a predominio de la derecha. Además se observa imagen hiperintensa aislada en corteza temporal del lado derecho.

drástica mejoría primero de la rigidez y luego los temblores. Durante toda la internación se realizó rehabilitación kinesiológica y fonaudiológica intensiva.

Debido al desarrolló de efectos adversos por L-dopa (alucinaciones) se redujeron las dosis y se repitió RM de cerebro que fue similar a la previa con difusión negativa. El EEG no presentó actividad epileptiforme.

Egresó para continuar rehabilitación en centro de tercer nivel con la siguiente medicación: levetiracetam $1.500 \mathrm{mg} /$ día, L-dopa 250/25 mg tres veces al día y meprednisona en reducción escalonada. Continúa en seguimiento ambulatorio, presentando al año del evento crisis comiciales y deterioro cognitivo mínimo.

\section{Discusión}

La EL fue descripta hace cientos de años por médicos como Hipócrates (460 a.C.-377 a.C.) y Thomas Sydenham (1624-1689). Tomó proporciones epidémicas entre los años 1916-1927 y fue denominada EL por von Economo quién publicó 27 artículos y un libro ${ }^{1,2}$. Jelliffe y Wimmer fueron los primeros en proponer que la EL fue provocada por la pandemia de influenza también conocida como gripe española ${ }^{3}$. Cruchet reportó los primeros casos de EL en el invierno de 1915-16 en Francia, y muy pocos casos fueron informados tiempo antes en la primavera de 1915 en Rumania ${ }^{3}$. 
En la epidemia entre los años 1916-1927 hubo cinco millones de afectados. Desde esa época sólo se describen casos esporádicos. Es una entidad que predomina en niños y adolescentes pero puede aparecer a cualquier edad y con igual preponderancia en ambos sexos ${ }^{2,4}$.

Con respecto a su etiología von Economo observó casos de EL tres años antes de la epidemia de influenza y muchos otros han sido descritos previamente por otros autores. En un reporte de 76 casos de EL sólo cuatro pacientes tuvieron influenza en los seis meses previos ${ }^{5}$. No pudo hallarse ARN de influenza en cerebros de autopsias de pacientes fallecidos con EL lo cual lo hace menos probable como agente causal directo ${ }^{6,7}$. Sin embargo, la falta de evidencia sobre la influenza no permite descartar completamente su participación como factor desencadenante.

La presencia de anticuerpos contra los ganglios basales (95\% de los pacientes), bandas oligoclonales en el LCR, y la respuesta a esteroides muestran la preponderancia de mecanismos autoinmunes en la fisiopatología de la $\mathrm{EL}^{2,4,8}$.

Los auto-antígenos de los ganglios basales en la EL, son similares a los hallados en la corea de Sydenham (40, 45 y $60 \mathrm{kDa})$, a diferencia de los de $98 \mathrm{kDa}$ que parecen ser específicos de la $\mathrm{EL}^{2,4,8}$.

Aún hoy el rol de un microorganismo precipitante en la EL es desconocido. Dado que los pacientes con EL suelen tener historia de afección previa de vías aéreas superiores (mayormente faringoamigdalitis), se ha intentado encontrar un agente etiológico infeccioso distinto de influenza como causante de la enfermedad.

Se sabe que el Streptococcus grupo A o pyogenes es causa frecuente de faringitis y es reconocida la disfunción de ganglios basales inmunomediada posterior en la corea de Sydenham y los desórdenes neuropsiquiátricos pediátricos asociados a infecciones estreptocócicas (PANDAS), aunque existe controversia entre la verdadera asociación del cuadro infeccioso con la disfunción de los ganglios basales en esta última entidad ${ }^{8,9}$.

Dale y col hallaron antiestreptolisina O (ASTO) elevado en $65 \%$ de los pacientes con EL y cierta asociación con faringitis previa ${ }^{2,4}$. Dado que en la corea de Sydenham sólo 73\% de los pacientes poseen ASTO elevado en suero los autores no descartaron completamente cierto rol del Streptococcus grupo A en la patogenia de la EL, si bien consideran que deben investigarse otras posibilidades ${ }^{2,4,8}$.
Se han descripto casos aislados de EL asociados a Bartonella henselae y virus de Epstein-Barr ${ }^{10,11}$.

Con respecto a los patrones clínicos, von Economo describió tres formas de presentación: 1) somnolencia y oftalmoplejía; 2) mutismo akinético; y 3) forma hiperkinética.

El florido espectro clínico incluye desórdenes del sueño (insomnio, somnolencia, inversión del ritmo de sueño), síndrome extrapiramidal, distonía, corea, hemibalismo, tics y secuelas neuropsiquiátricas (catatonía, desorden obsesivocompulsivo, mutismo, apatía, ansiedad). También se han descripto crisis oculógiras, oftalmoplejía, ptosis, y alteraciones en el control central cardiorrespiratorio, síntomas de hipertensión endocraneana como cefalea, fotofobia y meningismo. Algunos pacientes experimentan incontinencia de esfínteres. No suele haber síntomas piramidales, a diferencia de lo que ocurre en la meningoencefalitis por influenza. Puede haber parálisis de pares craneales y ataxia ${ }^{1,2,4}$.

Howard y Lees proponen siete criterios diagnósticos de EL, definiendo a una encefalitis aguda o subaguda con un promedio de tres de los siguientes (Tabla 1$)^{12}$.

Desde el año 2000 a la actualidad se han descripto aproximadamente 60 casos con un espectro clínico similar al observado por von Ecónomo ${ }^{13}$.

Los estudios de anatomía patológica evidencian infiltración linfocitaria perivascular, particularmente por células plasmáticas, sin cuerpos de inclusión virales, sin presencia de amiloide o complemento en ganglios basales. Suele observarse astrocitos y macrófagos activados. Los cambios crónicos incluyen pérdida neuronal y degeneración neurofibrilar ${ }^{2,5}$.

Los estudios complementarios sólo evidencian datos inespecíficos como hiperproteinorraquia.

Tabla 1. Criterios de encefalitis letárgica ${ }^{12}$

- Signos de compromiso de los ganglios basales
- Crisis oculógiras
- Oftalmoplejía
- Trastorno obsesivo-compulsivo
- Mutismo akinético
- Irregularidades respiratorias centrales
- Inversión del sueño o somnolencia que va a la letargia
y coma


La RM de cerebro suele evidenciar aumento de la señal en T2 en ganglios basales, tegmento, sustancia negra, tálamo, pedúnculos cerebrales y lóbulo temporal.

El EEG en la mayoría de los casos evidencia lentificación difusa y en una minoría actividad epileptiforme.

El diagnóstico diferencial debe hacerse con el PPE de otras etiologías, con la encefalitis de Bickerstaff, encefalitis de Rassmussen, encefalopatía de Hashimoto y encefalitis por anticuerpos antireceptor de $\mathrm{N}$-metil-D-aspartato (anti-NMDA) ${ }^{14}$. Este último es el diagnóstico diferencial más importante. La encefalitis con anticuerpos antiNMDA ha sido descripta principalmente asociada a teratomas de ovario, si bien en $40 \%$ no se asocia a cáncer ${ }^{15}$. Dale y col presentaron una serie de casos de EL, reportando que los pacientes anti-NMDA positivo son generalmente mujeres, más jóvenes, frecuentemente se presentan con diskinesias tempranas, agitación, insomnio, crisis oculógiras, conductas compulsivas y algunas veces con autoagresión siendo menos frecuente el parkinsonismo, que de estar presente, es de manifestación tardía. En nuestro paciente los anticuerpos anti-NMDA fueron negativos.

En cuanto al pronóstico, la recuperación completa ocurre en una minoría de pacientes, la mayoría persiste con trastornos psiquiátricos y movimientos anormales. El curso de la enfermedad suele ser monofásico.

La utilización de corticoides si bien es controversial, puede ser útil como en el paciente que describimos ${ }^{16}$. Ha sido descripto a su vez el uso de inmunoglobulina y plasmaféresis ${ }^{17}$.

Nuestro paciente presentó complicaciones asociadas al cuadro de rigidez y bradicinesia extrema, prolongando su internación por las intercurrencias infecciosas y exhibiendo una respuesta significativa a la administración de esteroides. La principal secuela del paciente fue la epilepsia secundaria a lesiones corticales temporo-insulares. La presencia de un cuadro de meningoencefalitis post infecciosa, seguido de un cuadro de akinesia que mejora posteriormente a la administración de dosis altas de esteroides nos hizo considerar el diagnóstico de encefalitis letárgica.

La EL es una entidad infrecuente, que requiere un alto índice de sospecha para evitar un retraso en el diagnóstico y ante el potencial beneficio del tratamiento con esteroides.

\section{Referencias}

1. von Economo C. Encephalitis lethargica. Wien Klin Wschr 1917; 30: 581-5.

2. Dale RC, Church AJ, Surtees RA, Lees AJ, Adcock JE, Harding B, et al. Encephalitis lethargica syndrome: 20 new cases and evidence of basal ganglia autoimmunity. Brain 2004; 127: 21-33.

3. Pearce JM. Baron Constantin von Economo and encephalitis lethargica. J Neurol Neurosurg Psychiatry 1996; 60: 167.

4. Vincent A. Encephalitis lethargica: part of a spectrum of post-streptococcal autoimmune diseases? Brain 2004; 127: 2-3.

5. McKenzie I. Discussion of epidemic encephalitis. Epidemiological considerations. BMJ 1927; 1: 532-4.

6. Maurizi CP. Influenza caused epidemic encephalitis (encephalitis lethargica): the circumstantial evidence and a challenge to the nonbelievers. Med Hypotheses 2010; 74: 798-801.

7. McCall S, Vilensky JA, Gilman S, Taubenberger JK. The relationship between encephalitis lethargica and influenza: a critical analysis. J Neurovirol 2008; 14: 177-85. Review.

8. Dale RC. Autoimmunity and the basal ganglia: new insights into old diseases. QJM 2003; 96: 183-91. Review.

9. Singer HS, Gilbert DL, Wolf DS, Mink JW, Kurlan R. Moving from PANDAS to CANS. J Pediatr 2012; 160 : 725-31. Review.

10. Brenneis C, Scherfler C, Engelhardt K, Helbok R, Brössner G, Beer R, et al. Encephalitis lethargica following Bartonella henselae infection. J Neurol 2007; 254: 546-7.

11. Alarcón F, Dueñas G, Lees A. Encephalitis lethargica due to Epstein-Barr virus infection. Mov Disord 2011; 26: 2132-4.

12. Howard RS, Lees AJ. Encephalitis lethargica. A report of four recent cases. Brain 1987; 110: 19-33.

13. López-Alberola R, Georgiou M, Sfakianakis GN, Singer C, Papapetropoulos S. Contemporary Encephalitis Lethargica: phenotype, laboratory findings and treatment outcomes. J Neurol 2009; 256: 396-404.

14. Benarroch EE. NMDA receptors: recent insights and clinical correlations. Neurology 2011; 76: 1750-7. Review.

15. Tan A, Shuey N, Bladin C. A modern perspective on the differential diagnosis between encephalitis lethargica or anti-NMDA-receptor encephalitis. J Clin Neurosci 2010; 17: 1204-6.

16. Ono Y, Manabe Y, Hamakawa Y, Omori N, Abe K. Steroid-responsive encephalitis lethargica syndrome with malignant catatonia. Intern Med 2007; 46: 307-10.

17. Maranis S, Tsouli S, Kyritsis AP. Encephalitis lethargica with quick response to immunoglobulin. Clin Neuropharmacol 2010; 33: 323-4. 